\title{
O negócio da tradução teatral visto do Brasil do século XIX
}

\section{The theater translation trade seen from nineteenth-century Brazil}

Paulo Marcos Cardoso Maciel $^{1}$ 


\section{Resumo}

O presente artigo objetiva discutir o negócio da tradução teatral visto do Brasil do século XIX partindo da identificação de alguns dos diferentes papéis que, segundo revelam os impressos teatrais e as crônicas teatrais do período, teriam sido a ela reservados na constituição da cultura dramática que circulava dentro e fora do país. Trajeto analítico que serve para compreensão mais geral da abrangência da tradução teatral de acordo com as fronteiras da circulação das peças teatrais impressas que, vistas de longe, destacam sua intensa e extensa presença na biblioteca dramática disponível entre 1800 e 1900, conforme constatamos nos rastros desse passado hoje depositados no acervo da Fundação Biblioteca Nacional.

Palavras-chave: Tradução teatral; cultura dramática; Brasil do século XIX; história do teatro
The present article aims to discuss the theater translation trade seen in Brazil from the 19th century, starting with the identification of some of the different roles that, according to the theatrical printed and theatrical chronicles of the period, would have been reserved for her in the constitution of the dramatic culture that circulated inside and outside the country. An analytical path that serves for a more general understanding of the scope of theatrical translation according to the boundaries of the circulation of the printed theatrical pieces which, seen from a distance, highlight its intense and extensive presence in the dramatic library available between 1800 and 1900, as we can see in the traces of this today deposited in the collection of the National Library Foundation.

Keywords: Theatrical translation; dramatic culture; nineteenth-century Brazil; theater history

E-ISSN: 2358.6958

1 Prof. Dr. Universidade Federal de Ouro Preto (UFOP) - paulinhomaciel@uol.com.br.

O artigo, inédito, é um dos resultados do projeto de pesquisa intitulado A biblioteca dramática brasileira 1800-1900 do acervo da Fundação Biblioteca Nacional, desenvolvido entre 2015 e 2016 com bolsa do Programa de Residência em Pesquisa na Biblioteca Nacional. 
Quem teve nas mãos um desses livros, em que a pagina escrita - ou melhor, transcrita - em dialeto está ao lado da tradução em língua italiana, não pode deixar de se perguntar, enquanto seus olhos transitavam inquietos de uma página a outra, se o verdadeiro lugar da poesia não estaria por acaso nem numa página nem outra, mas no espaço vazio entre elas. (Agamben, 2018, p. 110)

Não é tarefa simples e fácil pensar o papel que a tradução teatral teve na constituição da cultura dramática do Brasil no século XX, entre outros motivos, devido à inexistência de estudos mais sistemáticos, conforme lembrou em outra ocasião Beti Rabetti (2017, p. 50): "Fato é que quase nada a história do nosso teatro tem sobre o assunto, seja o geral sobre o lugar e o papel das traduções entre nós, seja o específico, sobre essa que seria a primeira tradução de Pirandello no Brasil". Esse esquecimento ou ausência de interesse dos estudos históricos pela tradução teatral assenta suas raízes, em parte, numa certa visão ou definição do teatro brasileiro que privilegiou, desde o século XIX, o ponto de vista dos melhores originais de autores brasileiros, conforme o critério de julgamento da produção dramática romântica adotado por Décio de Almeida Prado em O drama romântico brasileiro (1996, p. 22). De um lado, a história da cultura dramática no Brasil do século XIX aparece contada do ponto de vista dos melhores originais de autores brasileiros, o que, devemos lembrar, era a exceção e não a regra do palco local. Ao privilegiar esse repertório, a historiografia deixou de prestar atenção na rotina formada pelos autores e obras menores; por outro lado, levou à marginalização da contribuição das traduções e demais práticas de escrita para a his tória do teatro brasileiro. De outro lado, a história do teatro brasileiro contada apenas do ponto de vista das peças teatrais que foram encenadas, em contraste com o universo analisado por Décio, esqueceria as trocas efetivadas entre os diferentes agentes, meios e modos de comunicação e circulação dos repertórios, que permitem, aliás, situar melhor as escolhas específicas feitas nesse âmbito.

Devemos ter cuidado em generalizar a visão sobre as peças ou os textos teatrais enquanto "literatura dramática" sem antes compreender de que maneira, num dado contexto, as peças teatrais eram concebidas de acordo com as estantes do conhecimento e como se dava a circulação dos impressos teatrais entre as estantes e os palcos, pois, no universo da cultura dramática pesquisada, encontramos vestígios da passagem de determinados impressos pela cena como, por exemplo, quando os registros informam tratar de peça que foi acomodada ou adaptada à cena brasileira.

Os estudos históricos nos últimos tempos têm-se voltado para investigação do século XIX partindo de um conceito de teatro que vingou no século XX, após o surgimento da encenação, o que explica a predileção por objetos cênicos e espetaculares tidos como reveladores da efemeridade da arte teatral que, conforme observaremos no segmento A tradução teatral na cultura dramática do Brasil no século XIX do presente texto, contrastaria com a longa duração dos gêneros teatrais - peças teatrais que passaram a ser vistas e/ou designadas pela crítica segundo o conceito de literatura dramática e, portanto, meio à parte do teatro. Uma vez delimitado o negócio da tradução teatral segundo os dados de que dispomos sobre a circulação dos impressos teatrais, na segunda parte do trabalho, $A$ tradução diante da imagem ausente: a receptividade da crítica teatral brasileira, voltamos nossa atenção para a recepção 
pela crítica teatral brasileira do século XIX.

Não se trata de uma contraposição aos achados da historiografia do teatro brasileiro, pelo contrário, o que pretendemos é justamente descobrir de que maneira eles se comportam num território maior. Nesse sentido, o presente texto tem por objetivo contribuir para a reflexão sobre o papel histórico da tradução teatral na constituição da cultura dramática em circulação no Brasil do século XIX, sem com isso pretender escrever uma história a respeito do assunto. Com base em dados numéricos salientamos a relevância do tema partindo de levantamento de fontes já realizado a respeito da biblioteca dramática disponível no Brasil de 1800 a 1900. Os impressos teatrais se encontram depositados nas distintas seções, Obras Raras, Obras Gerais, Obras de referência e coleções, da Fundação Biblioteca Nacional.

Nessa direção, vamos compreender qual teria sido a importância da tradução teatral na história do teatro brasileiro do período com base nos dados gerais sobre a circulação dos impressos teatrais avulsos, localizados no acervo da instituição, acrescidos dos itens informados por catálogos que pertenceram a bibliotecas e livrarias do Brasil no século XIX. Dados não espelham nenhuma realidade, mas são indicadores de realidades possíveis ou prováveis - diríamos melhor, mensuráveis - que nos dizem acerca das regularidades e dos constrangimentos por trás das escolhas particulares. No caso específico da pesquisa de longa duração nos impressos teatrais identificamos: os locais de procedência, o universo dos autores e títulos de obras, a abrangência dos gêneros e das formas das peças teatrais, e suas várias práticas de escrita.

Por exemplo, a partir da segunda metade do século XIX, a cultura dramática no Brasil passou a contar com crescente oferta de títulos, autores e obras, de gêneros e práticas de escrita hoje esquecidos ou desconhecidos devido, conforme os dados assinalam, à ampliação e à expansão do mercado dos impressos teatrais que circulavam em grandes quantidades pelo mundo e impactavam, por sua vez, os caminhos e descaminhos do teatro brasileiro. Nesse mesmo momento, apontam esses dados, houve relevante aumento no número de traduções disponíveis e em circulação no país - se o comparássemos, por exemplo, com o das quatro primeiras décadas desse século, teríamos uma ideia mais nítida do impacto que teve esse aumento na constituição da cultura dramática do teatro brasileiro.

Os impressos teatrais de 1800 a 1900 nos mostram também de que maneira, nas suas últimas décadas, o território dramático se tornou disperso e de difícil classificação, situação que permite iluminar, aliás, a reação negativa da crítica teatral que, em parte, chegou a responsabilizar as traduções pelo estado, considerado deplorável, do teatro no país. As ferramentas de leitura e análise da recepção crítica do período, extraídas do sistema poético clássico-burguês, aparentemente não se ajustavam à crescente diversificação da produção entre 1860 e 1880, que parecia comprometer o quadro conceitual estabelecido. Desvela ainda essa fonte uma crescente diluição dos gêneros mais canônicos e tidos por tradicionais devido à intensa fragmentação da ação, à introdução de elementos líricos e épicos, ao hibridismo de gênero numa mesma peça, a práticas de escrita baseadas em procedimentos modernos de construção - indicadores do esgotamento do sistema de classificação oitocentista das 
peças teatrais.

A produção tornada e mantida periférica pela crítica (traduções, adaptações, paródias, acomodações, imitações) parecia ameaçar os limites conceituais da cultura dramática definida pela teoria dos gêneros teatrais então vigente e pelo projeto de teatro nacional reivindicado pelos cronistas e, mais tarde, pela historiografia do teatro brasileiro. Não podemos deixar de questionar também os marcos temporais (cronológicos) que, por assim dizer, informaram os juízos sobre o teatro brasileiro do século XIX, pois a sobrevivência dos gêneros teatrais na longa duração, mediante as inúmeras traduções e adaptações que os atualizam, desafia a estreita e perfeita sincronia entre o autor, a obra e seu tempo, perspectiva adotada pela maioria dos estudos históricos.

De um lado, a tradução teatral era vista como veículo ou meio legítimo de aprendizado da linguagem dramática pelos candidatos a dramaturgo locais que, por meio da imitação de modelos consagrados, desenvolveriam suas habilidades ou competências, conforme podemos constatar na "Carta sobre a atualidade do teatro entre nós", de Alvares de Azevedo, escrita provavelmente em 1851. De outro lado, era vista como empecilho a realização das ideias de teatro nacional defendidas pelos autores nos jornais e nas revistas. As diversas práticas da escrita dramática podem ser críticas ao revelar que a própria ideia de "original" consistia num dos mecanismos de controle e domínio do novo regime dramático francês ${ }^{2}$ ou, por outro lado, por parte de um determinado projeto de teatro nacional. Entre o velho regime português, o imperialismo parisiense e o nacionalismo local, se colocava a tradução teatral nesse contexto.

\section{A tradução teatral na cultura dramática do Brasil no século XIX}

Franco Moretti (2008), em A literatura vista de longe, observa que a diferença entre bibliotecas de acervos menor ou maior não compreende apenas a quantidade de seus títulos, pois também diz respeito à qualidade da experiência literária que elas têm a oferecer aos leitores. Dessa perspectiva, as fontes impressas, num total em torno de 1800 registros datados, nos ajudam na reconstituição da provável biblioteca dramática de 1800 e 1900 em circulação e disponível no Brasil do século XIX. Essa proposta abarcava o levantamento de todo e qualquer registro de peça teatral publicada entre 1800 e 1900 dentro e fora do Brasil e resultou num total de, mais ou menos, 1800 registros de impressos teatrais datados.

A investigação exigia cautela, pois trabalhava com dados brutos extraídos do acervo da Fundação Biblioteca Nacional (FBN), com aquilo que sobreviveu aos rastros desse passado dramático que hoje se encontra disponível para consulta na instituição. Pelo menos metade dos itens conta com indícios de seu antigo pertencimento, sendo os impressos teatrais oriundos de diversas bibliotecas públicas e ou privadas da época. Leitores importantes, como suas altezas reais, intelectuais e escri-

2 O estudo sobre a presença do novo regime dramático francês no Chile, de Francisco Javier González Errázuriz (s/d), nos mostra como esse processo de circulação na América Latina era acompanhado de um aparato importado de vida, costume e diversão, especialmente pelas elites urbanas. Assim, elas procuravam afirmar sua distinção não apenas com relação aos de baixo mas, também, à velha elite patriarcal. 
tores, além de colecionadores, aparecem entre os registros do depósito. Quanto às demais fontes impressas, nada conseguimos saber a respeito de sua proveniência até o presente momento.

Não privilegiamos o repertório encenado pois tínhamos em mente outro propósito: identificar de que maneira se forma uma cultura dramática no Brasil do século $\mathrm{XIX}$, quais os agentes, os meios e os mecanismos envolvidos em sua produção e circulação, quais eram seus possíveis caminhos de desenvolvimento para, então, avaliar como nesse outro território se comportavam as principais teses assentadas pela historiografia teatral sobre a questão. É preciso ainda levantar mais informações nos periódicos para compararmos, também, com os resultados alcançados pela historiografia e por meio dos registros de impressos teatrais. Também teremos condições de compreender melhor a dinâmica entre a página e o palco, o texto e a cena, lembrando que, nesse mesmo século, o mercado de impressos teatrais parece libertar definitivamente a cultura dramática de seu suporte cênico mais comum e usual de comunicação e existência, dados o tamanho e a forma desse mercado - Paris, Lisboa, Rio de Janeiro, Porto, Florença, Niterói, Maranhão, Pádua, Stuttgart, Nice, Trieste, Veneza, Madri, Londres, Santiago do Chile, são algumas da cidades citadas pelas fontes como locais de publicação -, o que, entretanto, não significa que deixou de existir vínculos entre os dois âmbitos.

Os dados revelam que havia cada vez mais pessoas interessadas em ler peça de teatro e, provavelmente, por motivos e razões diferentes; no caso do repertório clássico, objeto de inúmeras traduções, por exemplo, era usado como recurso didático e pedagógico para o ensino da língua francesa para as cortes europeias, e também brasileira, ao longo do século XIX (Sá, 2011). O que revela canais específicos de formação do público para e pelos impressos teatrais; afinal de contas, alguns leitores possivelmente eram ou se tornavam espectadores.

Desse modo, um olhar mais detido sobre os locais de publicação dos impressos teatrais revela o caráter desigual e combinado de sua circulação pelo mundo; num primeiro momento, o mapa das cidades de origem das fontes mostra como Lisboa e Porto contribuem com os gêneros poéticos do antigo regime português, as tragédias clássicas e os entremezes, por exemplo, que juntos com o melodrama dominam o repertório no Brasil durante as três primeiras décadas do século XIX. Não é por acaso que apresentam maior número de registros de peças designadas como tragédia do que Paris e Rio de Janeiro. Além dessas localidades, temos em ordem de importância: Porto, Florença, Londres, Maranhão, Niterói, Pádua, Stuttgart, Trieste e Veneza. Lisboa também contribui com o maior conjunto de registros de comédia, e na sequência temos Paris e Rio de Janeiro.

Nesse mesmo período, os impressos teatrais editados em Paris são, em maior número, de peças designadas por drama; as publicações feitas em Lisboa apresentam mais itens de sua variação: drama alegórico e drama histórico. Nesse sentido, a ampliação do repertório português se deve à incorporação (via tradução) de gêneros dramáticos do novo regime francês, como é o caso do drama histórico (romântico), situação não muito diferente das demais cidades, sobretudo das edições italianas e espanholas. Em geral, as traduções de obras completas nas línguas citadas eram 
de autores e obras daquilo que estamos chamando de novo regime dramático francês (drama romântico, drama realista, vaudeville etc.) para contrapor ao repertório clássico original e traduzido em francês, italiano, inglês e espanhol, encontrável, no passado, nas estantes de algumas bibliotecas particulares do Império. Veremos, por volta do final do século XIX, o esgotamento de ambos os regimes em razão da multiplicidade e da diversidade de gênero e escrita das peças teatrais.

As cidades italianas surgem no mapa da cultura dramática em circulação no século XIX, com as traduções de tragédias antigas publicadas em Florença, Pádua e Trieste, chegando até Stuttgart, na Alemanha. O mercado de tragédias antigas em francês aparece concentrado nas mãos dos editores de Paris (1834, 1835, 1834-1835, 1838) e, em segundo lugar, das tipografias e editoras cariocas (1832, 1837, 1839 duas traduções). Para as províncias e as cercanias da Corte ficam destinados o entremez saído em Niterói e um elogio dramático publicado no Maranhão. Por outro lado, a capital francesa já se destaca na década de 1830 pelo repertório ligeiro e lírico: vaudeville (1834) e cena lírica (1834-1835).

Os dados sobre os locais de publicação das peças contam uma pequena história sobre os gêneros poéticos, segundo a qual, com o tempo, alguns deles são relegados às margens das principais cidades envolvidas com o mercado de impressos teatrais e passam a circular pelas províncias e periferias do sistema dramático, estrangeiro e local. Nesse sentido, as traduções desempenhavam o papel crucial de garantir, por um lado, a hegemonia de um novo regime estrangeiro e local, e, por outro lado, desafiar a de um velho regime estrangeiro e local, resultando desse processo um complexo sistema de produção, circulação e recepção da cultura dramática disputada no mercado pelas peças teatrais, conforme exemplifica o caso do projeto editorial intitulado Archivo Theatral ${ }^{3}$.

A coleção foi incentivada e patrocinada pela "sociedade para a publicação de bons dramas" em colaboração com a Tipografia Carvalhense, e seu impacto e alcance podem ser medidos pela duração e regularidade da publicação, que contava com o lançamento de uma tradução por mês, e cujo repertório acompanhava os sucessos de palco das companhias francesas nos teatros da Rua dos Condes e do Salitre:

Durante cerca de 2 anos e quatro meses, a sociedade lisboeta acorria ao agora apelidado Teatro Francês para assistir, em língua francesa, às peças do repertório de uma companhia vinda de Paris, deixando-se seduzir, sobretudo, pela novidade do drama romântico, do melodrama e do vaudeville importado dos palcos dos teatros de boulevard. Nestas condições, era legítimo que se preservasse, no mundo editorial, aquilo que tinha sido o impulso dado no mundo do espetáculo. (Santos, 2011, p. 120)

O objetivo mais amplo era divulgar para o público lisboeta, que tivera ou não a oportunidade de ver as peças encenadas pelas companhias, o repertório francês que dominava o cenário teatral europeu e era considerado símbolo do cosmopolitismo, da civilidade e da atualidade da cena parisiense. Num primeiro momento, as edições

30 projeto editorial chamado Archivo Theatral foi criado por uma sociedade particular em Lisboa e resultou na publicação de cinco séries de textos ente os anos de 1838 e 1845. O seu principal objetivo era a renovação dos teatros da Rua dos Condes e do Salitre através da tradução do moderno repertorio francês (Santos, 2011). 
divulgaram os principais nomes do romantismo teatral na França e, posteriormente, destacaram os representantes do vaudeville, misturando autores, obras e gêneros distintos e até mesmo contrários. Assim, a eminente sociedade buscava empreender por meio de seu projeto editorial a renovação da cena portuguesa, substituindo a tragédia pelo "drama novo".

Na década de 1840, a coleção fez circular diversas peças francesas para o público lisboeta, que teve acesso mediante traduções e adaptações, ao repertório dos teatros Gaité, Porte Saint-Martin e Ódeon (Santos, 2011, p. 121). Neste sentido, as traduções pareciam destinadas pela "sociedade para publicação dos bons dramas" ao papel de agentes da renovação do repertório teatral do palco português sintonizando-o com o que era considerado o melhor do drama francês, segundo o critério dos envolvidos com o projeto editorial que, por sua vez, recebeu inúmeras críticas dos autores que defendiam os originais portugueses por considerar as traduções perniciosas ao teatro ou ao drama nacional que ambicionavam. A presença marcante de traduções no repertório teatral português ao lado da pequena produção nacional já se percebia desde o Oitocentos, como observou Sousa Bastos (1994, p. 147) no seu Dicionário de teatro português:

O nosso theatro está cheio de traducções de peças de todos os géneros. O theatro francez é principalmente a fonte inexgotavel a que recorrem os nossos traductores [...]. Muitas peças estrangeiras teem cahido entre nós pelas pessimas traducções que d'ellas fazem. Todavia, o que é certo é que o nosso publico é muito menos indulgente para as peças originaes do que para as traduzidas. Em cada época theatral, termo medio, representam-se nos theatros de Lisboa, vinte peças originaes e não menos de cem traducções!

A coleção foi publicada uma década depois no Rio de Janeiro, também dividida em cinco séries, mas, com modificações com relação ao repertorio saído em Lisboa e, segundo os dados de que dispomos, sob a responsabilidade da Typ. Imp. E Const. De J. Villeneuve e Comp.:

1a Série:

Abranches, Antonio Joaquim da Silva (1807-1868). O captivo de fez, Rio de Janeiro, 1841; Carre, Almeida (1799-1854). Um auto de Gil Vicente, Rio de Janeiro, 1842; O alfageme de Santarem ou A espada do condestável, Rio de Janeiro, 1842; Voltaire, Fraçois Mariet Azout de (1694-1779). Alzira ou Os americanos, Rio de Janeiro,1842; Brueys, David Augustin de (1640-1723). O ralhador, Rio de Janeiro, 1842; Diogo Tinoco ou A corte de D. João II em 1484, Rio de Janeiro, 1842; Pellico, Silvio (1788-1854). Francisca de Rimin, Rio de Janeiro, 1842; Regnard, Jean François (1655-1709). O jogador, Rio de Janeiro, 1842; Rosier, Marguerite Henry. O Castello de Montlouvier, Rio de Janeiro, 1842.

2 Série:

Garret, Almeida (1799-1854). Merope, Rio de Janeiro, 1842; Racine, Jean Baptiste (1639-1699). Mithridates, Rio de Janeiro, 1842; Silva, Antonio Diniz da Cruz e (1731-1799). O falso heroísmo, Rio de Janeiro, 1842; Cunha, Vicente Pedro Nolasco da (1773-1744). Alonso e Cora ou O Triunpho da natureza, Rio de Janeiro, 1843; Beaumarchais, Pierre Augustin Caron de (1732-1799). Os dous amigos ou o negociante de Lyão, Rio de Janeiro, 1843; Campos Junior, Joaquim Pereira de. Os templários, Rio de Janeiro, 1843; Diderot, Denis (1713-1784). O pai de família, Rio de Janeiro, 1843; Dumas Fils, Alexandre (1824-1895). O marido da viúva, Rio de Janeiro, 1843; Gomes, Junior, João Batista. Nova Castro, 
Rio de Janeiro, 1843; Hugo, Victor Maria, Comte, (1802-1885). Maria Tudor, Rio de Janeiro, 1843; Ruy Braz, Rio de Janeiro, 1843.

3a Série:

Sousa, Henrique Guilherme de. Afonso III, ou o valido D'El Rei, Rio de Janeiro, 1843; Corneille, Pierre (1606-1684). D. Ruy Cid de Bivar, Rio de Janeiro, 1843; Garrick, David (1717-1779). O casamento clandestino, Rio de Janeiro, 1843; La Touche, M de. Iphigenia em Tauride, Rio de Janeiro, 1843; Longepierre, Hilaire-Bernard de; Roqueveyne, Baron de (1659-1721). Medea, Rio de Janeiro, 1843; Molière, Jean-Baptiste Coquelin (1622-1673). Tartufo ou Hypocrita, Rio de Janeiro, 1843; Di Lucca, Cesar Perini (1807-1848). O conde andeiro, Rio de Janeiro, 1844; Di Lucca, Cesar Perini (1807-1848). O Marquez de Pombal ou Vinte e um anos de sua administração, Rio de Janeiro, 1844; Melo, Antonio Firmino da Silva Campos e (1804-). D. Rodrigo, Rio de Janeiro, 1844; Metastasio, Pietro Antonio Domenico Buonaventura (1698-1782). Régulo, Rio de Janeiro, 1844; Ribeiro, Maximiniano Pedro de Araujo. O poético heroísmo, Rio de Janeiro, 1844.

4a Série:

Scribe, Augustin Eugène (1791-1861). Um erro, Rio de Janeiro, 1844; Garret, Almeida. Frei Luis de Souza, Rio de Janeiro, 1844; Ferreira, Antonio (1528-1569). O cioso: comedia em tres actos, Rio de Janeiro, 1844; Seneca, Lucius Annaeus. Hippolyto, Rio de Janeiro, 1845; XXX, pseud. Os dous primos, Rio de Janeiro, 1845; Bouchardy, Joseph (1810-1870). O sineiro de São Paulo, Rio de Janeiro, 1845; Bandouin, Jean Marie Théodore. Os dous sargentos, Rio de Janeiro, 1845; Ribeiro, Maximiano Pedro de Araújo. Montezume, Rei do Mexico ou Os combates de ódio e de amor, Rio de Janeiro, 1845; O velho de vinte e cinco anos, Rio de Janeiro, 1845.

5a Série:

Ribeiro, Maximiano Pedro de Araújo. Constantino O grande ou A Ambição castigada por si mesma, Rio de Janeiro, 1846; Beaumarchais, Pierre Augustin Caron de (1732-1799). O casamento de Figaro ou As loucuras de um dia, Rio de Janeiro, 1846; Loureiro, Jacinto Heliodoro de Faria Aguiar de (1806-). Alvaro Gonçalves, o Magriço e os Doze de Inglaterra, Rio de Janeiro, 1846; Mallefille, Pierre Jean Félicien (1813-1868). Glenarvon Ou Os puritanos de Londres, Rio de Janeiro, 1846; Pichard, Louis Benoît (1769-1828). O engeitado, Rio de Janeiro, 1846; Ronsard, François (1814-1867). Lucrecia, Rio de Janeiro, 1846; Silva, Joaquim Norberto de Sousa, 1820-1891. Clytemnestra, rainha de Mycenas, Rio de Janeiro, 1846; Racine, Jean-Baptiste (1639-1699). Phedra, Rio de Janeiro, 1847; Silva, Antonio José da (1705-1739). Guerras do Alecrim e Mangerona, Rio de Janeiro, 1847; Dias, Antonio Gonçalves (1823-1864). Leonor de Mendonça, Rio de Janeiro, 1847; Crébillon, Prosper Jolyot de (1674-1762). Rhadamistho, Rio de Janeiro, 1849.

A Typ. Imp. e Const. de J. Villeneuve e Comp. (Typographia de J. Villeneuve $\&$ C., Typographia do Jornal do Commmercio de Rodrigues \& C) surgiu com a compra do Jornal do Commercio, no dia 9 de junho de 1832, por Junius Constancio de Villeneuve e R. A. Mongenot. Nesse sentido, os dados coletados indicam que a tradução teatral desempenhou importante papel na discussão e na elaboração de distintos projetos teatrais e políticos nacionais pelo mundo afora. Os dramas históricos, as peças bem-feitas, os vaudevilles, os gêneros poéticos e as práticas da escrita teatral viajavam e, assim, tinham que se haver com as questões colocadas em cada chegada, em cada contexto, pelas diferentes perspectivas acerca dos teatros nacionais que ocupavam então a agenda de artistas e intelectuais.

Cinquenta anos depois, o mapa dos impressos teatrais mostra algumas mudanças importantes no que diz respeito, especialmente, ao mercado dos gêneros 
dramáticos. As edições publicadas em Madri e Milão disputam com as parisienses a maior parte do mercado da comedia na década de 1880. Vale lembrar que os resultados aqui apresentados são específicos pois desdobrados de um determinado acervo de impressos teatrais que precisaria ser checado com listas bibliográficas publicadas nos países aqui citados, portanto, compreende a perspectiva do mercado a partir do olhar daqueles que selecionaram, por sua vez, os itens pesquisados. Nesse quesito, o Rio de Janeiro aparece no quarto lugar seguido das cidades de Bogotá, Lisboa, Nice, Porto, São Paulo e Turim. Ao contrário, porém, da regularidade editorial parisiense, as publicações saídas nas duas principais concorrentes no mercado da comédia dos anos 1800 estão concentradas em determinado período do intercurso e, por outro lado, devem sua maior incidência à catalogação do acervo, pois são títulos avulsos que, originalmente, faziam parte de uma mesma coleção, geralmente, de peças pertencentes às chamadas obras completas. Esse tipo de edição, em geral, era destinado à publicação dos autores clássicos: no caso da Espanha, os representantes do século de ouro; no caso da Franca, os clássicos franceses e antigos; em Londres, Shakespeare.

A geografia da comédia em circulação com os impressos teatrais do século XIX se expandiu nessa passagem de 50 anos incorporando ainda várias cidades ao circuito de distribuição. No caso de Lisboa, no entanto, os registros desse período informam o provável encolhimento de seu mercado editorial dramático ou de seu comércio de impressos teatrais; dessa maneira, os dados sinalizam mudanças no comércio dramático da capital portuguesa com a corte brasileira e vice-versa. Cabe lembrar que o posto de liderança após o domínio português, nas três primeiras décadas do século, foi ocupado pelo Rio de Janeiro durante 40 anos (1840-1880). Na década de 1880, o Rio de Janeiro perde para Paris o primeiro lugar no número de publicações teatrais.

Por outro lado, os dados coletados no acervo servem para observarmos o crescente imperialismo teatral parisiense exercido ao longo do século XIX, direta ou indiretamente, sobre todas as demais cidades. Em termos do mercado das peças teatrais, entretanto, esse domínio absoluto foi alcançado nas duas últimas décadas do século XIX. Nesse período, a cidade desbanca o Rio de Janeiro e concentra, aliás, o maior número de registros de traduções de comédia e drama. Lisboa e Porto se tornam praças periféricas, como a franja latino-americana: Bogotá, Caracas e Santiago. Os registros de tragédia diminuem significativamente revelando sua crise no mercado dos gêneros dramáticos, contando apenas 15 registros e, em sua maioria, de impressos publicados em Paris $(1880,1882,1889)$.

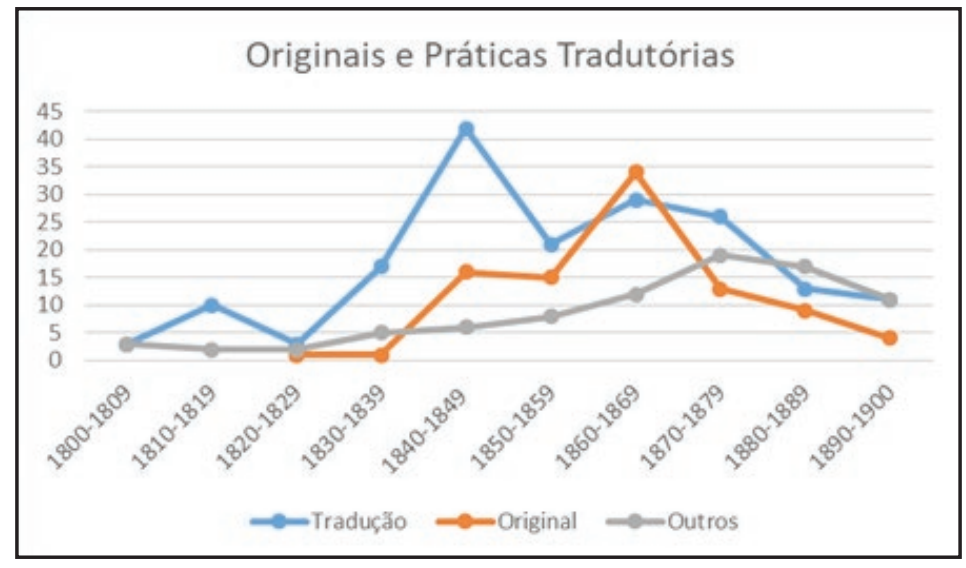


A maior ramificação dos impressos teatrais por gêneros poéticos do mercado dramático, na segunda metade do século XIX, acompanhou a expansão e diversificação das práticas de escrita: acomodações, adaptações, traduções, versões livres. O total dessas práticas soma, entre 1800 e 1900, 358 registros de impressos teatrais em circulação. Entre eles, os registros de tradução formam a maioria das entradas encontradas, algo em torno de 197 itens. Em seguida temos, em ordem decrescente: originais (94), versões (17), imitações (13), traduções livres (10), arranjos (8), paródias (6), acomodações (5), adaptações (3), reduções (2), coordenações (2) e imitação livre (1). Tais indicadores são importantes se levarmos em conta a geografia dos gêneros poéticos do drama pois, assim, servem como um mapa de referência para compreendermos melhor a forma de contribuição das traduções e demais práticas de escrita para a constituição da cultura dramática no Brasil do século XIX. Portanto, os números não devem ser lidos em termos absolutos, ou, então como uma espécie de retrato do mercado.

Hoje seria impensável nos depararmos no mercado das peças teatrais impressas com essa diversidade e multiplicidade de práticas de escrita aceitas e, provavelmente, reveladoras da parca institucionalização da escrita teatral e da autoridade intelectual sobre os produtos desse setor específico. Não temos como saber de que forma cada uma dessas práticas concebia as relações entre os textos e, assim, perceber que distância mantinham entre si, pois, para isso, teríamos que consultar diretamente os textos.

O estudo de Linda Huchteon (1985) Uma teoria da parodia nos ajuda, em parte, na discriminação das diferentes operações de leitura e escrita intertextuais que encontramos sinalizadas pelas peças teatrais impressas. A autora observou que nem todas as formas de paródia têm tom desafiador e mordaz; por exemplo, a imitação clássica e renascentista era antes uma forma de tributo ao mestre-modelo e, ao mesmo tempo, uma apropriação ou incorporação que visava suplantá-lo, numa espécie de emulação. Por outro lado, a paródia também não deve ser confundida com o burlesco e o ridículo, que são apenas casos dela, mas não esgotam seu sentido mais amplo, como lembra a teórica. Nem devemos tomá-la pelo pastiche, que opera "mais por semelhança e correspondência" do que pela distância, ou melhor, pela repetição com diferença: "a paródia é, ao mesmo tempo, duplicação textual (que unifica e reconcilia) e (que coloca em primeiro plano a oposição irreconciliável entre textos e entre texto e "mundo"). (Huchteon, 1985, p. 129).

A paródia pode ser comparada à farsa, ao burlesco, à citação e alusão, mas lembrando que seu raio de ação ou seu éthos de repetição é quase sempre "intramural", isto é, não visa, como a sátira, à correção dos vícios ou à defesa da reforma da sociedade ou dos homens. Por não ser um gênero de escrita simples, exige de seus praticantes e intérpretes um saber decodificador que "construa um segundo sentido através de interferências acerca de afirmações superficiais e complemente o primeiro plano com o conhecimento e reconhecimento de um contexto de fundo" (Huchteon, 1985, p. 50-51).

O conceito amplo de paródia usado pela autora, mesmo oferecendo uma chave de análise comparativa válida da repetição com diferença e revelando meios básicos 
de seu mecanismo de funcionamento, não esgota o sentido dos distintos modos de operação das relações entre textos. Por exemplo, a divisa entre a tradução e a imitação era traçada menos nitidamente no século XVIII do que viria a ser no século XIX, embora fosse situada em diferentes pontos por diferentes indivíduos, conforme observou Peter Burke (2009, p. 38). De acordo com o historiador francês, nas traduções desse período podiam ser observados diversos procedimentos como, por exemplo, a contração, expurgos e a ampliação que, juntos, alteravam substancialmente a forma das peças, regime que persistiu até o século XVIII, conforme salientou $(2009$, p. 40): “Em alguns casos, a ação dos diálogos, das peças e histórias eram transferidas de um local para outro, processo que pode ser descrito em termos musicais como 'transposição', ou - seguindo a prática dos atuais tradutores de software - como 'localização'. Peças traduzidas, por exemplo, eram situadas em novos locais, mais familiares para novos públicos".

Neste sentido, as semelhanças e diferenças entre as distintas praticas, incorporadas ao termo geral de parodia pela autora, precisariam ainda ser pensadas ou vistas em termos histórico-conceituais de acordo com os usos feitos pelos atores e num dado contexto. Para Machado de Assis, por exemplo, havia uma diferença significativa entre tradução e paródia mesmo que, ambas, tivessem em comum a concorrência desleal aos originais de autores brasileiros, pois contavam com a preferência dos empresários teatrais, segundo argumentou em suas crônicas. As crônicas teatrais do século XIX nos aproximam, assim, da tradução teatral mais ligada ao palco, ao processo de adaptação do texto à economia teatral e cênica das companhias, portanto, muitas vezes praticada a pedido dos empresários teatrais. O tradutor/ensaiador surge no papel de mediador entre o texto ponto de partida e o palco ponto de chegada e, entre os dois espaços, se colocava também o ponto que, no fim das contas, era o agente que orientava, segundo as marcações feitas no texto, o desempenho de atores, atrizes e técnicos de cena.

De acordo com a bibliografia especializada (Amorim, 2005, Huchteon, 2013), o limite entre tradução e adaptação tem-se tornado tênue e poroso, relativamente indefinido em alguns enfoques, uma questão complexa que, por sua vez, tem levado a teoria contemporânea ao aprimoramento de instrumentos e métodos de pesquisa e a estudos mais adequados. Nesse sentido, os autores têm reconhecido que a diferença entre as duas práticas de escrita dependia e depende, em parte, de acordos teóricos, explícitos ou não, forjados pela comunidade de tradutores, editores e ou escritores, das exigências do mercado em torno da fidelidade ao original, etc., ou seja, conforme as distintas formas econômicas, políticas, sociais e culturais aceitas ou não da propriedade intelectual e artística. Esses fatores contingentes reunidos num determinado momento do passado também serviram para aferir a qualidade, a fidelidade e o alcance das traduções levadas à cena no Brasil do século XIX. Nesse contexto crítico, havia clara distinção entre a tradução teatral e a paródia, sendo esta última vista como uma escrita menor e, além disso, perniciosa, pois podia corromper, até mesmo moralmente, os originais locais.

Em geral, a recepção crítica às traduções esteve pautada em alguns critérios básicos - a qualidade, a moralidade e a nacionalidade - principais que nortearam, 
apesar das especificidades, o julgamento feito do repertório dramático informado até aqui. Nesse sentido, as traduções eram criticadas e, ao mesmo tempo, tidas como necessárias ao projeto burguês de teatro nacional. De que maneira a crítica reagiu à diversificação e ampliação do repertório dramático devidas aos múltiplos gêneros e às diferentes práticas de escrita emergentes no final do século XIX e que desafiariam as noções de origem, autoria e obra que se desejavam fixadas em determinados gêneros poéticos, valores morais e nacionalidades? Veremos algumas das respostas dadas à questão.

\title{
A tradução diante da imagem ausente: a receptividade da crítica teatral brasileira
}

\begin{abstract}
A semelhança reunida, reconhecida, recluída, a semelhança evidente por si mesma nunca é senão uma salvação de aparência. A semelhança aquieta, ela nos afasta do hic. Mas, quando surge a semelhança - ou seja, quando ela aparece por aparição, por inevidência, por inquietude, por abertura e por estranhamento: quando, por exemplo, "a noite revela-se feita de órgãos e preenchida de uma espera física"-, ela não revela nada menos, seja por equívoco ou por desvio, que uma "verdade" fundamental impossível de ser dita de outra maneira (Didi-Hubermann, 2011).
\end{abstract}

Não podemos pensar sobre o negócio da tradução teatral no Brasil do século XIX sem considerarmos ao longo desse percurso a participação, dentre os demais agentes envolvidos no esquema, dos escritores candidatos a dramaturgos brasileiros. Através de seus testemunhos podemos observar de que maneira existiam naquele contexto, pelo menos, duas noções distintas de tradução: a dos críticos e aquela que regia as escolhas dos empresários teatrais, segundo nos informam as crônicas do período que, aqui nos valem como fontes para investigarmos a recepção às traduções teatrais que circulavam no contexto. Guardadas as devidas diferenças entre as posições dos autores é possível notar que, em seu horizonte de expectativas, estava uma ideia de teatro nacional que parecia na contramão da força da tradução registrada pelas mesmas crônicas.

Conforme observamos no início do texto, contamos com poucos estudos a respeito do problema da tradução teatral por parte da historiografia do teatro brasileiro, além dos que vem desenvolvendo Rabetti $(2016 ; 2017)$, e, muito menos, quando se trata de recensear os juízos da crítica teatral no Brasil do século XIX. Neste sentido, o repertorio critico aqui apresentado decorre do anteriormente reunido por Joao Roberto Faria em Ideias teatrais: o século XIX no Brasil (2001) e, sendo assim, apresenta um recorte diferente da primeira parte de nosso estudo, pois não estamos nos baseando num mapeamento mais amplo das crônicas teatrais do período em destaque. Por outro lado, vale lembrar que a maioria dos críticos -cronistas aqui discutidos era também de escritores candidatos a dramaturgos brasileiros e, dessa maneira, diretamente interessados no assunto.

Após localizarmos a tradução teatral no quadro da cultura dramática disponível no Brasil do século XIX, neste segundo momento vamos entender de que maneira a crítica colocou o problema. Álvares de Azevedo, em carta escrita provavelmente em 1851, lamentou o estado deplorável do nosso meio teatral que, grosso modo, estaria 
limitado apenas às figuras de João Caetano e Ludovina Soares da Costa. Segundo o autor, portanto, não havia mesmo condições de chegar a uma boa concepção dramática: "os melhores dramas de Schiller, Goethe, de Dumas não se realizam como devem. O Sardanapalo, de Byron, traduzido por uma pena talentosa, foi julgado impossível se levar-se a cena" (Azevedo apud Faria, 2001, p. 358). Neste sentido, o autor aconselhou a mocidade laboriosa a empreender trabalhos dramáticos começando pelo estudo das traduções do teatro espanhol de Calderón de La Barca e Lope de Vega, do teatro cômico inglês de Shakespeare até Sheridan, do teatro francês de Molière, Regnard, Beaumarchais - e mais modernamente enriquecido pelo repertório de Scribe e pelos provérbios de Leclercq e de Alfredo de Musset (Azevedo apud Faria, 2001, p. 359).

O problema não era a tradução, mas sua má qualidade devida aos limites da recepção do palco nacional. Uma forma de superar esse estado lamentável estaria nos esforços da juventude que, com base no estudo das traduções, escreveria originais brasileiros de melhor qualidade, pois, baseados numa cultura dramática fundamentada na estante dos teatros tidos como clássicos, inglês, espanhol e francês, além do moderno drama francês. O destino das traduções é pedagógico, pois se trata de educar os candidatos a dramaturgos locais. Nem todos os críticos, porém, pareciam concordar nesse quesito; em Da arte dramática no Brasil, publicado em 1844, no Minerva Brasiliense, do Rio de Janeiro, Émile Adet constatava a inexistência da literatura dramática no Brasil, de um lado, devido ao pouco número de originais, e, de outro lado, pelo fato de a maioria das obras nacionais ser imitação ou tradução de outras, conforme salientou: "Possui o Brasil uma literatura dramática? Não, pois não é sem dúvida um número muito limitado de composições deste gênero, a maior parte das vezes imitadas ou traduzidas, que a poderia formar" (Adet, 1844, p. 155).

Em seguida, no mesmo artigo, reconhece que uma literatura dramática não nasce simplesmente dos esforços de alguns indivíduos, pois determinados fatos objetivos impediriam as tentativas feitas de alcançar seus objetivos e, sendo assim, melhor seria voltar a atenção para o baixo nível da literatura de imitação existente, conforme observou: "existem fatos materiais que se opõem ao desenvolvimento, não de uma literatura dramática original, ao menos não o presumimos; porém de uma literatura de imitação, minimamente preferível à nulidade" (Ibidem). Uma literatura de imitação seria preferível à nulidade, sustenta o autor sua posição no debate, contrariando até as expectativas pedagógicas de Alvares de Azevedo, pois não era favorável às traduções do repertório francês, especialmente de seus "dramas febricitantes" (Ibidem). Caso não vencêssemos os obstáculos materiais ao desenvolvimento de uma literatura dramática local, deveríamos ficar satisfeitos com a resposta dada ao problema pelo crítico.

O problema da tradução teatral no Brasil do século XIX era pensado, pela crítica periódica selecionada para o presente artigo, segundo os termos da teoria dos gêneros vigente, que os escalonava hierarquicamente entre dois extremos: a tragédia e a comédia. Hierarquia dos gêneros dramáticos que foi revista pela teoria do drama burguês de Denis Diderot na França do século XVIII e modificada pela introdução do drama doméstico e da comédia lacrimosa junto ao repertório mais tradicional, no sé- 
culo XIX. No interior desse regime poético clássico-burguês, o burlesco e as demais formas consideradas inverossímeis, imorais, menores e impuras são marginalizadas, como, por exemplo, o maravilhoso, a tragicomédia e a farsa. A questão dos gêneros poéticos orientava a discussão da crítica sobre o papel da imitação e da tradução na constituição de determinada cultura dramática local que, contrariamente a seus propósitos civilizatórios e nacionalistas, parecia reticente e resistente ao projeto único de teatro nacional alardeado nas páginas dos jornais.

Assim, o que havia naquele momento era uma disputa em torno dos gêneros poéticos por agentes e instituições envolvidos com o comércio e a circulação teatral e dramática que, aqui, compreendia os caminhos do teatro brasileiro. Disputa que esbarrava na qualidade e na moralidade do gênero das traduções diante de um ou outro original brasileiro julgado, pelo crítico, merecedor de aplauso. Atitude crítica que pode ser encontrada na crônica "Folha Dramática", de Justiniano José da Rocha, publicada originalmente em $O$ cronista de 23 de novembro de 1836, sobretudo em seu comentário ao drama $O$ cioso de si mesmo, de Antônio Xavier:

Esse drama não é das produções do teatro francês, rapidamente traduzidas, que continuamente sobem a nosso tablado; nós o devemos à pena do autor de Zulmi$r a$, e isso ainda lhe é mais um merecimento, que não são somente os Dumas, os Hugos que sabem onde fica a fonte de nossas lágrimas, que as sabem fazer derramar: é riqueza própria e não traduzida, é riqueza nossa e não emprestada, é pois esse drama que deve formar a escola brasileira, e se algum dia as imaginações de nossos patrícios se voltarem para as produções dramáticas, o espírito desse drama deve presidir as suas novas composições. (p. 65)

O problema dizia respeito à rapidez com que eram feitas as traduções do teatro francês para subir ao palco local, mas também resvala para a moralidade daquilo que seria próprio do nosso caráter do texto segundo, é claro, o novo drama do autor de Zulmira. Defendendo uma saída local para a formação de um repertório nacional, a tradução teatral passou a ser vista como um obstáculo à consolidação ou constituição do teatro nacional, e, assim, a função da crítica passou a ser de definição das bases estéticas, sociais e políticas necessárias ao projeto.

A tese da ausência da literatura dramática comprometia o próprio objeto da crônica, pois, se ela não existe, o que está sendo julgado pelo crítico? Decerto a própria ausência. Dessa forma, as traduções se tornaram seus sinais mais evidentes. Um ou outro original brasileiro não serve para formar uma literatura dramática, seria preciso, antes de tudo, deixar de ser uma literatura copista, conforme observou Machado de Assis (apud Faria, 2001, p. 413) numa carta a José de Alencar datada de 1868: "O mal da nossa poesia contemporânea é ser copista - no dizer, nas ideias e nas imagens". O autor voltou à carga crítica na crônica "Ideias sobre teatro", recriminou os empresários teatrais que privilegiam as traduções, em detrimentos dos originais brasileiros, por conta do lucro auferido no negócio: "é uma mina o estrangeiro, há sempre que tomar a mão; e as inteligências não são máquinas dispostas às vontades e conveniências especulativas" (Machado, 1859, p.1).

Em virtude disso, Machado de Assis chamou atenção para o aparecimento da figura do tradutor dramático que, segundo observou, seria uma "espécie de criado de 
servir que passa, de uma sala a outra, os pratos de uma cozinha estranha" $(1859$, p. 1). Nesse sentido, o tradutor dramático transplantaria, para o Brasil, concepções estranhas ao meio, não sendo capaz de enxergar, segundo o autor, o que se move debaixo das mãos. Não bastava, portanto, ter uma literatura dramática; era preciso que ela fosse original e, de preferência, educativa, como alegavam os críticos em nome do repertório realista. Do contrário, segundo sentenciou o autor (1859, p. 2), a literatura dramática no Brasil não passaria de uma galeria, um grupo furta-cor, uma associação de nacionalidades.

Uma associação de nacionalidades era o que formava a cultura dramática mais ampla do período. Essa postura crítica diante da tradução teatral ganhou fundamento com a perspectiva romântica em virtude da tomada de consciência histórica pelos autores do desenvolvimento da literatura dramática, segundo esclarece a carta de Agrário de Menezes (apud Faria, 2001, p. 381) dirigida ao secretário do Conservatório Dramático do Rio de Janeiro e publicada em 1857: ela "não é a mesma em todos os tempos, não é a mesma em todos os países".

Os autores parecem divergir no que concerne aos modelos teatrais para o bem do Brasil, porém compartilham da mesma opinião a respeito da má qualidade das traduções nascidas de mãos inábeis e incompetentes, conforme comentou Henrique Cezar Muzio em crônica publicada a respeito do drama Os mineiros da desgraça, de Quintino Bocaiúva, em 28 de julho de 1861, no Diário do Rio de Janeiro:

Os nossos teatros podem ser frequentados por milhares de espectadores, mas só com a condição de representar os piores dramas franceses, traduzidos, em geral, por quem ignora as duas línguas, ou então insulsas rapsódias do moderno teatro português, cujos primores deixam de parte, porque dizem que o público os não entende! (Muzio, 1861, p. 1)

Para desgosto do cronista, os nossos teatros não pareciam interessados em destinar, aos milhares de espectadores, dramas franceses sem que fossem deturpados, a tal ponto, que o coitado do público não conseguia mais acompanhar seu desenvolvimento com clareza. Nem tudo, porém, parecia perdido no teatro brasileiro para a crítica; Raul Pompeia (apud Faria, 2001, p. 598) em crônica publicada no Jornal do Commercio do Rio de Janeiro, em 12 de janeiro de 1890, salientou a lotação dos teatros:

Durante alguns dias de novembro, a população desertou dos teatros, como a significar que a alegria popular vem da confiança na ordem. O alarme passou logo e os teatros todos animam-se, com um entusiasmo de renovamento, e a alegria dos que se divertem na tranquilidade, desdobra-se do Variedades com o Gato Preto, para os Cavaleiros Andantes do Santana, e daí para os Filhos do Capitão Grant do Recreio.

Machado de Assis argumentava em $O$ theatro nacional, publicado originalmente na Revista dramática, do Rio de Janeiro, de 13 de fevereiro de 1866, que o abandono do teatro clássico no Brasil do século XIX não favoreceu nem o romantismo, nem o realismo, muito pelo contrário, teria sido substituído pelos gêneros cômicos e ligeiros, informados aqui por Raul Pompeia (apud. Faria, 2001, pp. 556-562). Deve- 
mos perguntar até que ponto as crônicas expressavam ou não um sentimento geral acerca das traduções teatrais. Lembrando que, segundo a crítica, elas atendiam ao interesse dos empresários teatrais que, assim, economizavam com o pagamento dos originais e, ao mesmo tempo, podiam dispor do texto com inteira liberdade, sem as barreiras da autoridade intelectual.

O romancista se batia por uma imagem coesa e sem fraturas do teatro e do Brasil no século XIX, conforme salientou: "A civilização perde assim a unidade. A arte destinada a caminhar na vanguarda do povo como uma preceptora - vai copiar as sociedades ultra-fronteiras" (Machado, 1859, p. 2). Desse modo, o autor via seu objeto desaparecer sob suas mãos enquanto tinha diante de si uma galeria furta-cor das nacionalidades (Ibidem). Os tradutores brasileiros cometiam uma dupla infidelidade com a literatura dramática local, deturpando os textos estrangeiros e traindo os originais brasileiros. Estrangeiro em seu país, o teatro brasileiro para existir precisaria tomar distância da Europa e superar sua monstruosa imagem, imagem caracterizada pela multiplicidade e variedade de origens, gêneros e práticas de escrita que, a partir da segunda metade do século XIX, desafiaram os critérios e instrumentos de leitura e análise vigentes.

Para finalizarmos esse segundo segmento e passarmos às considerações finais vamos voltar ao começo à imagem ausente: o teatro nacional. Do ponto de vista da crítica, a retirada dos originais de autores brasileiros do cartaz dos teatros da Corte do Rio de Janeiro seria, antes de tudo, decorrente da estratégia dos empresários para diminuir os custos com os direitos e, ao mesmo tempo, dispor como conviesse dos textos teatrais. $O$ teatro brasileiro não seria nem nacional nem estrangeiro e, em razão disto, poderíamos dizer que ele aparece diante dos críticos-cronistas como uma coisa disforme ou informe, pois sua imagem se torna semelhante a uma associação de nacionalidades (Assis, 1859, p. 2), na qual, a sua própria não está presente. Uma imagem sem contornos limitados, homogêneos, claros e definidos conforme exigia a estética da semelhança clássica e burguesa do teatro nacional informada pela pena dos autores. Empenhada e interessada, uma parte da crítica teatral evoca uma realidade ausente e busca tornar visível, através das palavras, a invisibilidade do seu próprio objeto (teatro nacional), pois, perdido ou corrompido por baixo das mãos ligeiras do tradutor teatral, enquanto, outra parte julgava as traduções necessárias para se alcançar um espelhamento civilizado do próprio objeto ausente.

\section{Considerações finais}

Nosso objetivo aqui foi o de reunir alguns indícios dos diferentes papéis e significados assumidos pela tradução teatral ao longo da constituição da cultura dramática no Brasil do século XIX. Em decorrência das opções feitas, não houve espaço, no texto, para uma reflexão mais detida sobre a questão em torno de alguns nomes de tradutores informados pelas fontes impressas, isso fica para outra oportunidade. A tradução dos impressos teatrais foi fundamental para a circulação, divulgação e socialização de um vasto repertório internacional dentro e fora do Brasil, marcado, antes de tudo, pelo imperialismo parisiense responsável pelo desenvolvimento desi- 
gual e combinado das nacionalidades no âmbito das histórias da cultura dramática em Portugal, Espanha e Itália, nesse mesmo período.

Nesse contexto, as traduções teatrais eram vistas ora como meios pedagógicos importantes na formação dos candidatos a dramaturgos no país, ora como obstáculo a seu aprendizado, pois os distanciava das culturas nacionais. Eram tomadas por sinais evidentes de uma literatura dramática que não passava de mera cópia malfeita dos originais europeus ou eram tidas por sinais promissores de que podíamos superar, por meio do estudo, os concorrentes estrangeiros. Uma literatura dramática exilada de seu país e de seu tempo, segundo aparece resumida nas crônicas e cartas publicadas. Juízo estético, econômico, político e moral que, devido à quantidade relevante das traduções teatrais, se desdobrava num conjunto de medidas endereçadas ao poder público e por sua vez destinadas pelo Estado à orientação e à canalização do fluxo de autores, obras, gêneros, escritas e nacionalidades, perante o crescente e complexo mercado da cultura dramática no Brasil do século XIX.

O que pode ser feito com os indícios aqui reunidos sobre a presença da tradução teatral no Brasil do século XIX é situar seu contexto cultural incluindo, nesse trajeto, conforme observou Peter Burke (2009, p. 17): "os sistemas ou 'regimes' de tradução prevalentes nesse período - em outras palavras, as regras, normas ou convenções que governam sua prática, tanto os fins (ou 'estratégias') como os meios (as 'táticas' ou 'poéticas')". A visão geral esboçada procurou encontrar respostas provisórias para algumas das seis perguntas tomadas ao questionário elaborado pelo historiador francês: quem traduz, com que intenção, o que se traduz, para quem se traduz, de que maneira e com que consequências (Burke, 2009, p. 14-36).

Para finalizar o raciocínio gostaria de recuperar a epígrafe deste texto para sugerir que, talvez, a tradução teatral estaria mais bem situada nesse espaço vazio entre o dialeto e a língua italiana onde, segundo o autor, também mora a poesia. Espaço que, segundo o conceito de tradução de Paul Ricoeur, e o da hospitalidade linguística, conforme disse (2005, p. 43): "Parece-me, de facto, que a tradução não coloca apenas um problema intelectual, teórico ou prático, mas um problema ético. Conduzir o leitor ao autor, conduzir o autor ao leitor, correndo o risco de servir e trair dois amos, e pôr em prática aquilo que me apraz designar por hospitalidade linguística". Hospitalidade nem sempre garantida, nem mesmo partilhada e recebida igualmente entre todas as línguas que teriam mais a ganhar com o luto da tradução perfeita e da ideia do original absoluto abrindo, com esse gesto, lugar no mundo para a aceitação da diferença do próprio e do estrangeiro (Ricoeur, 2005, p. 19). 


\section{Referências}

ADET, Emile. Da arte dramática no Brasil. Minerva Brasiliense: jornal de sciencias, lettras e artes, Rio de Janeiro, n. 5, vol. 1, jan. 1844, pp. 154-157.

AGAMBEN, Giorgio. O fogo e o relato: ensaios sobre criação, escrita, arte e livros. Trad. Andrea Santurbano, Patricia Peterle. São Paulo: Boitempo, 2018.

AMORIM, Lauro Maia. Tradução e adaptação: encruzilhadas da textualidade em Alice no País das Maravilhas, de Lewis Carrol, e Kim, de Rudyard Kipling. São Paulo: Editora Unesp, 2005.

ASSIS, Machado de. Ideias sobre o teatro. $O$ espelho: revista de litteratura, modas, indústria e artes, Rio de Janeiro, n. 5, 02 de out. 1859, p. 1-2.

BASTOS, Sousa. [1908]. Dicionário de teatro português. Coimbra: Minerva, 1994.

BURKE, Peter; HSIA, R. Po-chia (orgs.). A tradução cultural. Trad. Roger Maioli dos Santos. São Paulo: Editora Unesp, 2009.

DIDI-HUBERMANN, Georges. De semelhança a semelhança. Alea, Vol. 13, N. 1, Janeiro-Junho, 2011.

ERRÁZURIZ, Francisco Javier González. Influencia francesa en la vida social de Chile de la segunda mitad del siglo XIX., s/d. Disponível em: http://www.uai.cl/images/sitio/ docentes/documentos/influencia_francesa_en_chile.pdf. Acesso em: 24 set. 2017.

FARIA, João Roberto. Ideias teatrais: o século XIX no Brasil. São Paulo: Perspectiva; Fapesp, 2001.

HUTCHEON, Linda. Uma teoria da adaptação. Trad. André Cechinel. Florianópolis: Editora UFSC, 2013. (2 ${ }^{\text {a }}$ ed.)

HUTCHEON, Linda. Uma teoria da paródia: ensinamentos das formas de arte do século XX. Trad. Teresa Louro Péres. Rio de Janeiro: Edições 70, 1985.

MORETTI, Franco. A literatura vista de longe. Trad. Anselmo Pessoa Neto. Porto Alegre: Arquipélago editorial, 2008.

MUZIO, Henrique Cezar. Parte Litteraria - Theatro do Gymnasio - Os mineiros da desgraca, drama em 4 atos, por Quintino de Souza Bocayuva. Diário do Rio de Janeiro: folha politica, litttearia e comercial, Rio de Janeiro, Ano XLI, n. 203, 26 jul. 1861, p.1. 
POMPÉIA, Raul. Folhetim do Jornal do Commercio - Aos domingos. Jornal do Commercio, Rio de Janeiro, Ano 68, n. 12, 12 de jan. 1890, p. 1.

PRADO, Décio de Almeida. O drama romântico brasileiro. São Paulo: Perspectiva, 1996.

RABETTI, Maria de Lourdes. Pois é.. isso!: trânsitos e transações da tradução teatral. Anais do IX Congresso da Abrace, Uberlândia, MG, 2016, pp. 2370- 2394. Disponível em: www.even3.com.br/Anais/IXCongressoABRACE/32303-POIS-E-ISSO---TRANSITOS-E-TRANSACOES-DA-TRADUCAO-TEATRAL. Acesso em: 26 jul. 2019.

RABETTI, Maria de Lourdes. Em busca da tradução teatral: o trabalho do historiador em meio a miudezas da cena e precariedades documentais. Sala Preta, v. 17, n. 2, 2017, p. 48-71.

RICOEUR, Paul. Sobre a tradução. Trad. Maria Jorge Vilar de Figueiredo. Lisboa: Edições Cotovia, 2005.

ROCHA, Justiniano José da. Folha dramática - Theatro da Praia de D. Manuel. O cioso de si mesmo, drama em 3 atos. O chronista, n. 17, 23 de nov. 1836, pp. 65-67.

SÁ, Mafra de. O teatro como estratégia educativa no Segundo Império: características de uma dramaturgia idealizada pelo Conservatório Dramático brasileiro. Anais VI Congresso Brasileiro da História da Educação, Vitória, ES, maio, 2011. Disponível em: http://www.sbhe.org.br/novo/congressos/cbhe6/anais_vi_cbhe/conteudo/ file/1129.pdf. Acesso em: 24 set. 2017.

SANTOS, Ana Clara. O Archivo Theatral: uma coleção de teatro francês. Arquivo Solto Sinais de cena 15, 2011, p.119-124.

Recebido em: 25/06/2019 Aprovado em: 10/07/2019 